\title{
Masonry bell towers: dynamic considerations
}

Salvador Ivorra PhD

Senior Lecturer, Departamento de Ingeniería de la Construcción, Obras Públicas e Infraestructura Urbana, Universidad de Alicante, Spain

Francisco J. Pallarés PhD

Senior Lecturer, Departamento de Física Aplicada, Universidad Politécnica de Valencia, Spain

\section{Jose M. Adam PhD}

Senior Lecturer, ICITECH, Departamento de Ingeniería de la Construcción y Proyectos de Ingeniería Civil, Universidad Politécnica de Valencia, Spain

The building of masonry bell towers was customary in Europe until the beginning of the twentieth century. At the present time, most of the work carried out on these structures involves either conservation or rehabilitation, owing to their considerable historical value. One of the forces that can have an influence on the behaviour of a bell tower is that caused by the turning/oscillation of the bells themselves. This is a dynamic force and may interact with the tower's natural frequencies. This paper describes the effect of bell-ringing on masonry towers. The towers are classified and a series of data are offered to characterise their behaviour. Finally, a procedure is described that permits an assessment to be made of this type of structure.

\section{Introduction}

The building of masonry bell towers was customary in Europe until the beginning of the twentieth century. At the present time, owing to their considerable historical value, most of the work carried out on these structures is either conservation or rehabilitation.

One of the strongest forces to which belfries are subjected is that caused by the turning/oscillation of the bells. These forces vary through time and their value depends on the way in which the bells are made to ring. The three most frequently used systems are the Central European, the English and the Spanish (Ivorra et al., 2006). In the first, the bells are swung around their axes through an angle that can vary from $55^{\circ}$ to $160^{\circ}$ from one country to another. In the English system, the bells describe a complete circle $\left(360^{\circ}\right)$, changing the direction of the swing in each cycle. In both of these systems the bells are very much out of balance and rest on specially designed bellframes inside the towers. In the Spanish system, the bells are provided with a large counterweight, which means they are well balanced. In addition, they are usually fixed directly to the tower windows and always turn in the same direction.

The earliest studies on problems associated with the ringing of bells that turned a complete circle $\left(360^{\circ}\right)$ were carried out by $\mathrm{E}$. H. Lewis in 1913-14: 'Experiments at All Saints Church, Loughborough' and 'Calculation of the forces acting upon a church tower when bells are rung'. The data obtained by Lewis were later collected by Heywood (1914). After these studies, various papers were published that investigated the problems brought about by the dynamic interaction between the turning/ oscillation frequency of the bells and the natural frequencies of the towers. These included works by Müller (1968), who was responsible for the introduction of DIN 4178 (DIN, 2005) for bells operating with the Central European system. Also worthy of mention are the studies carried out by Niederwanger (1985), Steiner (1986) and Wölfel and Schalk (1996) in Germany and Bennati et al. (2005a, 2005b) in Italy.

Regarding the masonry towers containing bells that follow the English system, besides the above-mentioned study by Lewis, also important are those by Clouston (1970), who investigated the effects of bells that turned through $360^{\circ}$, and also those by Wilson and Selby, who installed measuring equipment and studied many towers in their work on the effects of the dynamic forces generated by the ringing of bells (Wilson and Selby, 1993; Selby and Wilson, 1997).

The number of studies carried out on the Spanish bell operating system is considerably smaller. The work done by Ivorra et al. (2005) and Ivorra and Pallares (2006) can be mentioned here. These authors studied masonry bell towers subjected to the dynamic forces caused by bell-ringing.

Mathematical equations of both horizontal and vertical forces introduced by the bells on the supports are included in Equations 1 and 2. These equations are obtained from Figure 1, without taking into account the weight of the bell clapper (Ivorra et al., 2006).

$$
\text { 1. } H(t)=M a\left[(\dot{\phi})^{2} \sin \phi(t)-\ddot{\phi} \cos \phi(t)\right]
$$

2. $V(t)=-M g-M a\left[(\dot{\phi})^{2} \cos \phi(t)+\ddot{\phi} \sin \phi(t)\right]$

where $a$ is the distance of $\mathrm{G}_{1}$ from $\mathrm{C}_{1}$ (where $\mathrm{G}_{1}$ is the bell 


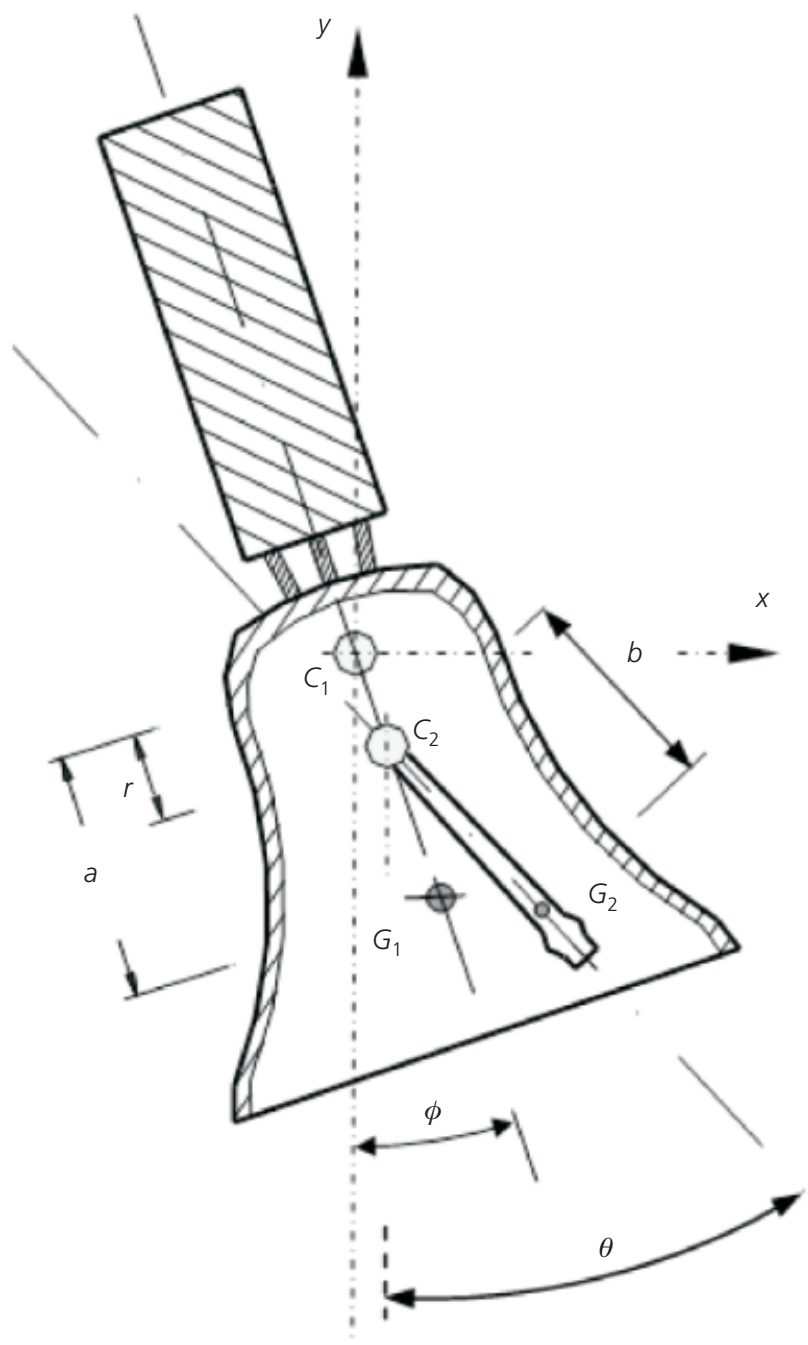

Figure 1. Bell simplified model (d) wall belfries constructed on top of one of the nave/church walls, see Figure 3(b).

A variety of factors can influence tower behaviour.

(a) Bending and torsion stiffness of the tower. The mechanical characteristics of construction materials and tower section and height also play important roles.

(b) The way in which the tower is connected to other elements of the church/nave.

(c) Initial inclination of the tower.

(d) Stiffness and characteristics of the foundation and variations in the groundwater level.

(e) Tower mass and its distribution along its height.

( $f$ ) Structural damping.

(g) Distortion of bell frames.

\section{Mechanical characteristics of the construction materials employed}

The construction materials used in bell towers are usually obtained from the raw materials existing in the vicinity. This factor, together with the construction typology employed, means that each tower is individual and unique.

Walls are usually built of considerable thickness. In most cases, they consist of a sandwich-type construction with exterior layers of bricks or masonry with ashlars and filler material in the middle. In many of the towers, the thickness and material characteristics vary with height, since construction might have taken place in various stages.

Taking these factors into consideration, a description of the dynamic behaviour of the tower necessarily depends on knowledge of the mean dynamic behaviour of the material of which it is composed. In order to determine the mechanical parameters of the material used in the construction of the tower, a combination of experimental tests and numerical models previously calibrated from the test results is normally used. One of the latest techniques for obtaining the dynamic properties of masonry structures was presented by Gentile and Saisi (2007), who proposed estimating tower dynamic behaviour from experimental tests, using a different elasticity modulus for different zones of the tower. In this work, natural frequencies are obtained from the accelerations measured in different points of the tower by using ambient vibration. Damping ratio is obtained in the same way by using forced vibration.

The experimental procedure described allows the characteristics of the tower's masonry to be determined from the structure's 


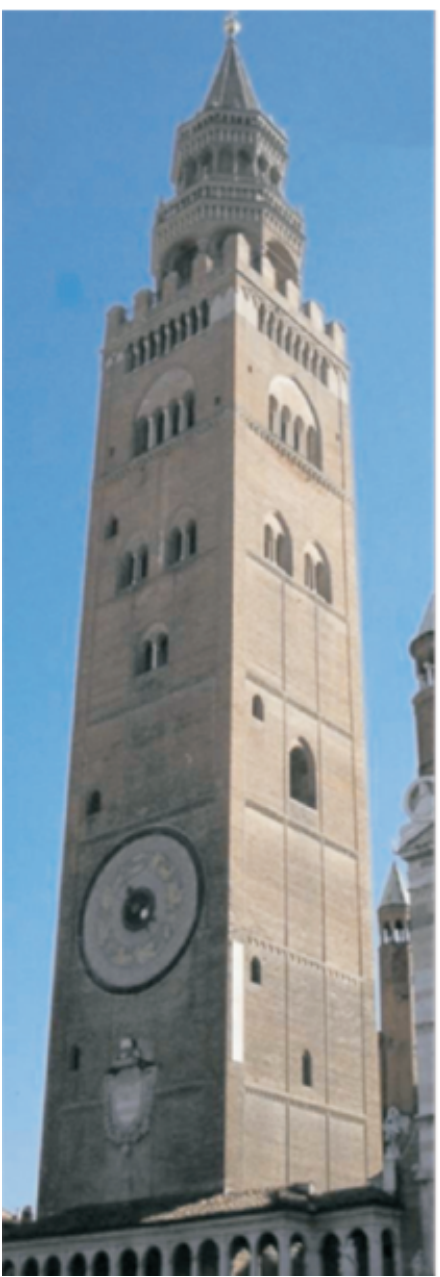

(a)

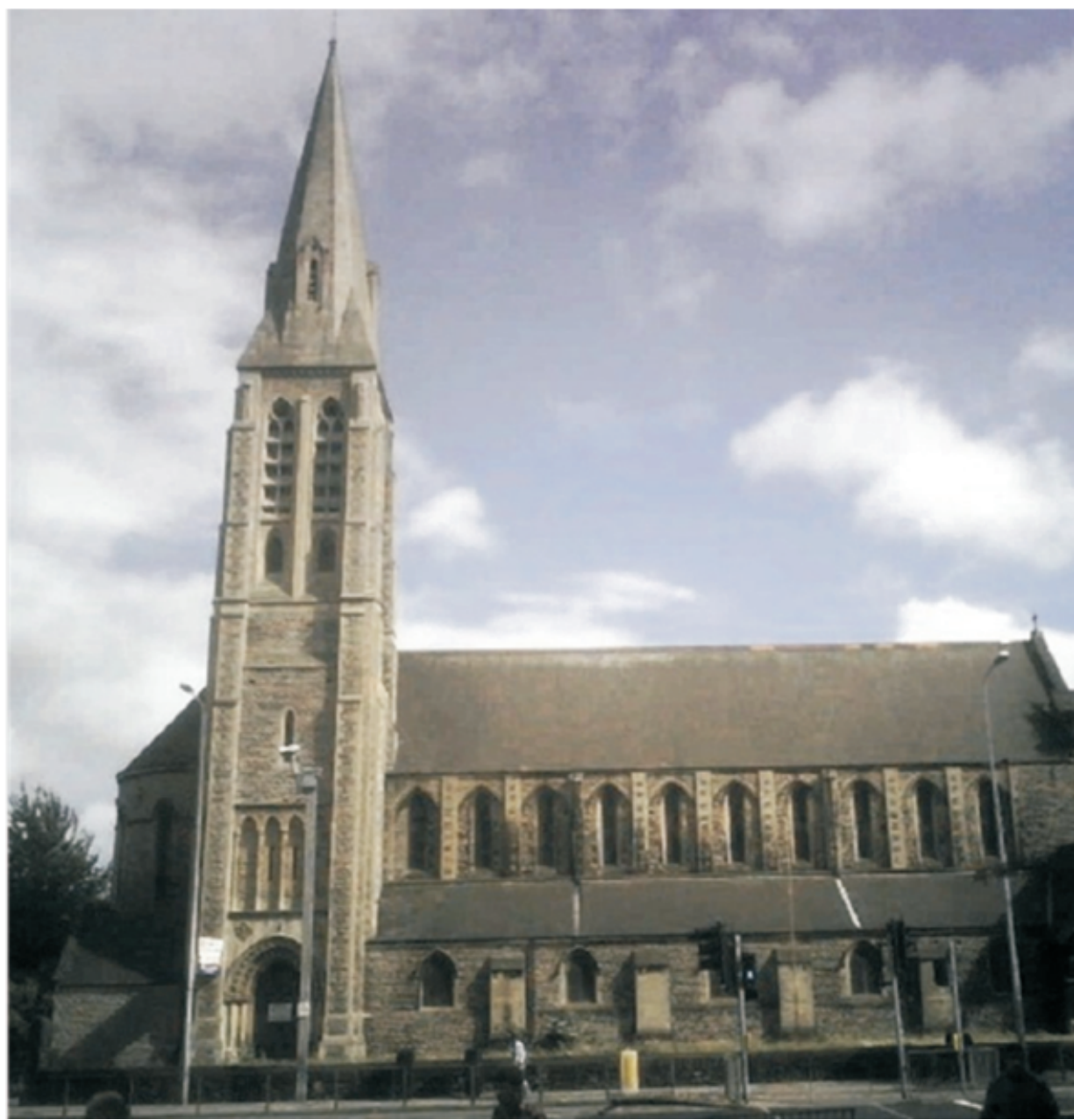

(b)

Figure 2. (a) Torrazzo di Cremona (Italy); (b) St James Church, Cardiff (UK)

natural frequencies. From these data a numerical model is calibrated using the tower's dynamic elasticity modulus as control parameter until the modal response is identical for the experimental and numerical cases. Table 1 shows an order of value of the masonry dynamic elasticity modulus. A wide disparity can be observed in the values.

To evaluate tower behaviour in response to dynamic excitation, it is important to take into consideration the non-linearity of the material and possible cracks as a result of the excitation. There are various existing behaviour models to characterise masonry, based on the material's compression and tensile strengths. Compression and tensile strength values of masonry also present a very wide range, largely dependent on a wall's configuration and the materials of which it is composed. To serve as a comparison, Table 2 gives the experimental results obtained by different authors in studies on masonry bell towers.
The mass of the masonry tower is another parameter necessary for the evaluation of dynamic behaviour. This factor is directly related to material density. As with the other parameters, there is great diversity in the results obtained by different authors. In most cases, the density can be said to be within the $12-18 \mathrm{kN} / \mathrm{m}^{3}$ range.

\section{Global dynamic behaviour}

In the previous section, certain characteristics were described that allowed masonry to be defined as a material; however, a bell tower's dynamic behaviour also depends on other factors such as mass, stiffness and damping. The tower behaviour and its possible dynamic interaction with the turning/oscillation of the bells basically depend on the tower's natural frequencies and their damping.

These structures are, in general, relatively flexible to horizontal 
Masonry bell towers: dynamic

considerations

Ivorra, Pallarés and Adam

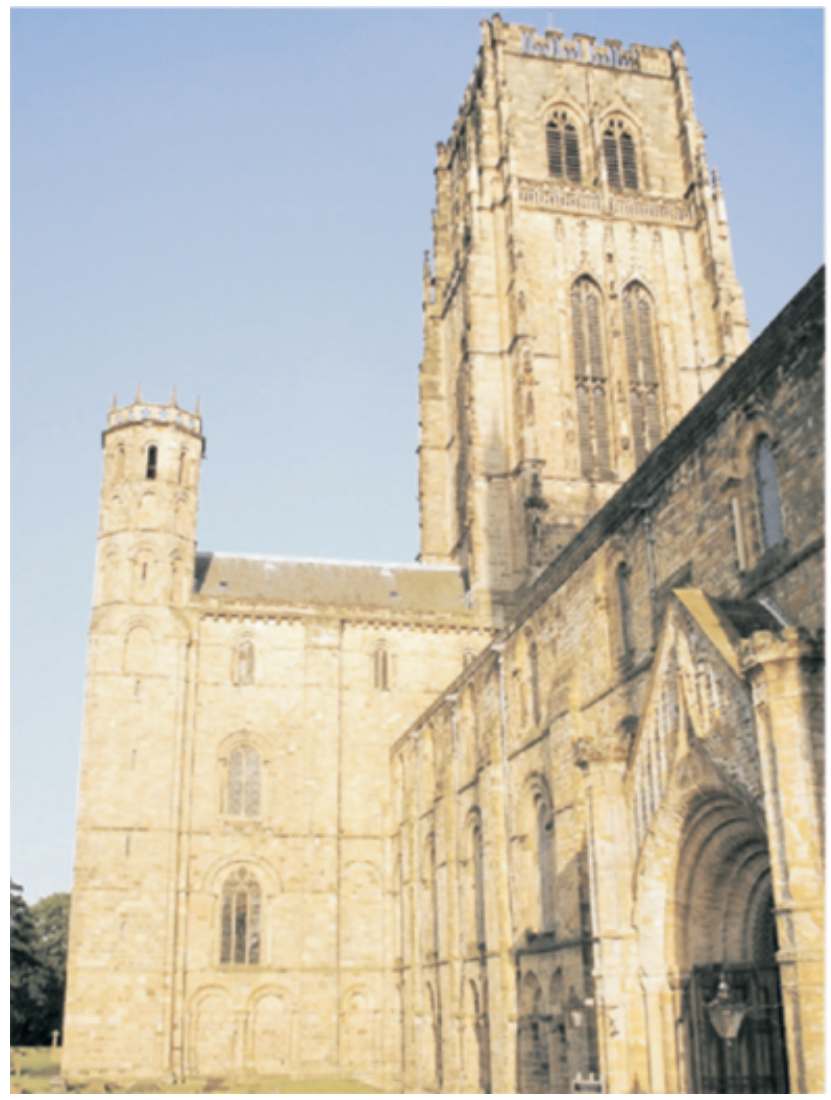

(a)

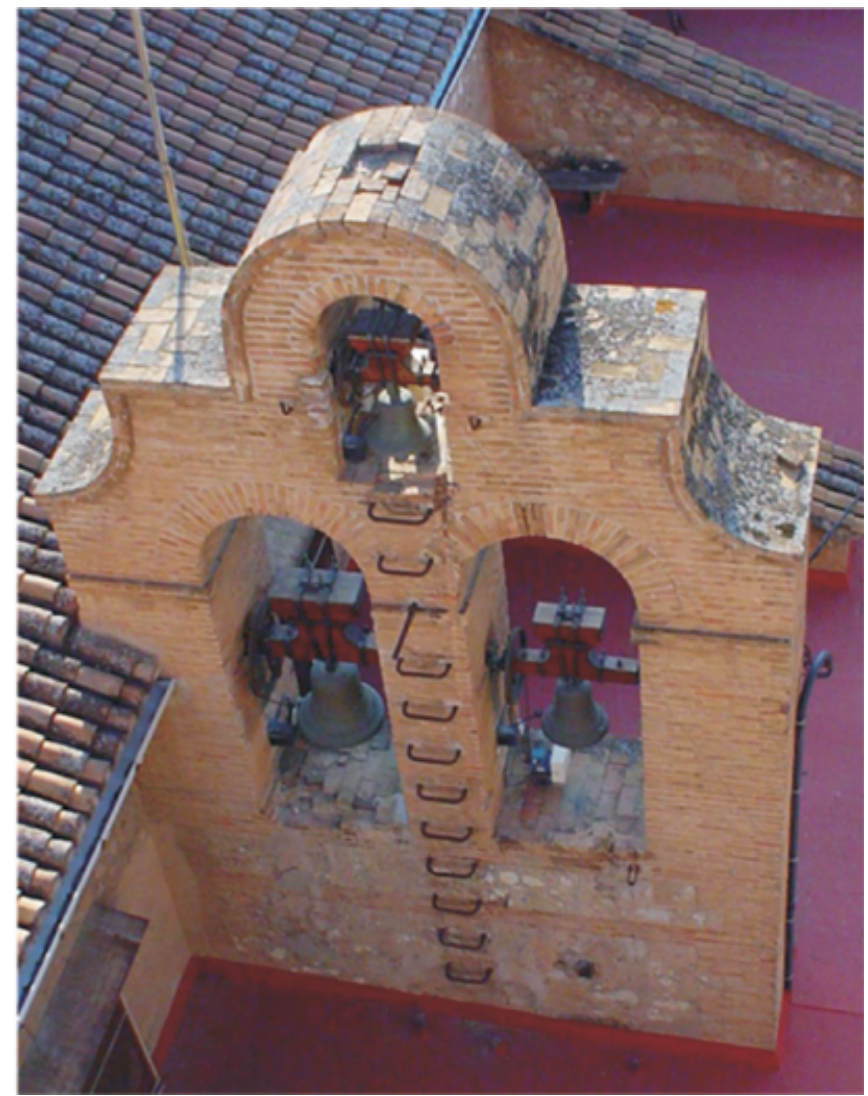

(b)

Figure 3. (a) Durham Cathedral; (b) wall belfry of the Carmelitas Church. Valencia (Spain)

\section{Reference}

Elasticity modulus: $\mathrm{MPa}$

Abruzzese and Vari (2004)

Benedettini and Gentile (2007)

4000

DIN 4178 (DIN, 2005)

Gentile and Saisi (2007)

Julio et al. (2008)

Schmidt (2007)

Wilson and Selby (1993)

1800-5000

3000-7000

$1718-1772$

4800

1000

1425

Table 1. Dynamic elasticity modulus for masonry

\begin{tabular}{llc}
\hline Reference & $f_{\mathrm{c}}: \mathrm{MPa}$ & $f_{\mathrm{t}}: \mathrm{MPa}$ \\
\hline Abruzzese and Vari (2004) & $3 \cdot 0$ & $0 \cdot 5$ \\
Carpinteri et al. (2005) & $2 \cdot 0$ & 0.3 \\
Ivorra and Pallares (2007) & $2 \cdot 0$ & $0 \cdot 4$ \\
Modena et al. (2002) & $4 \cdot 0-12 \cdot 0$ & -
\end{tabular}

Table 2. Compression $\left(f_{\mathrm{c}}\right)$ and tensile $\left(f_{\mathrm{t}}\right)$ strength of masonry

movements, as can be seen from the low natural frequency that they present. Table 3 shows the values for the first natural frequency obtained by various authors for masonry towers.

The first natural frequency value usually corresponds to one of the tower's bending frequencies, as does the second, and the third is generally a natural torsion frequency. Table 3 shows a comparative study of the classification of different vibration modes obtained by different authors in European masonry towers.

Figure 4 shows the dynamic behaviour of a 15th century Gothic tower obtained from the calibration of a numerical model with experimental results. The methodology used to determine the masonry's mechanical parameters is that described in the previous section.

Another characteristic peculiar to masonry bell towers is their low damping coefficient, in the $1 \cdot 5-2 \cdot 5 \%$ range. Table 4 gives a comparison of the experimental values obtained by different authors. The fact that the damping coefficient is so low usually causes a high dynamic amplification factor when the excitation frequencies from the turning/oscillation of the bells come close to one of the tower's natural frequencies. 
Structures and Buildings

Volume 164 Issue SB1
Masonry bell towers: dynamic

considerations

Ivorra, Pallarés and Adam

\begin{tabular}{|c|c|c|c|c|}
\hline \multirow[t]{2}{*}{ Reference } & \multirow[t]{2}{*}{ Tower height: m } & \multicolumn{3}{|c|}{ Natural frequencies: $\mathrm{Hz}$} \\
\hline & & $1 \mathrm{st}$ & 2nd & $3 r d$ \\
\hline Abruzzese and Vari (2004) & $33 \cdot 1$ & $2 \cdot 00$ & $2 \cdot 17$ & $6 \cdot 70$ \\
\hline Benedettini and Gentile (2007) & $48 \cdot 0$ & 1.46 & - & - \\
\hline Binda et al. (2000) & $112 \cdot 0$ & 0.44 & 0.45 & 1.66 \\
\hline Carpinteri et al. (2005) & $39 \cdot 0$ & $0 \cdot 12$ & - & - \\
\hline Gentile and Saisi (2007) & $74 \cdot 0$ & 0.59 & 0.71 & $2 \cdot 46$ \\
\hline Ivorra and Pallares (2007) & $35 \cdot 5$ & $2 \cdot 30$ & $2 \cdot 40$ & $5 \cdot 50$ \\
\hline Julio et al. (2008) & $33 \cdot 0$ & $2 \cdot 13$ & $2 \cdot 47$ & $6 \cdot 56$ \\
\hline Lund et al. (1995) & $24 \cdot 8$ & $2 \cdot 01$ & $2 \cdot 05$ & - \\
\hline Lund et al. (1995) & $43 \cdot 5$ & $1 \cdot 38$ & $1 \cdot 82$ & - \\
\hline Lund et al. (1995) & $66 \cdot 0$ & $1 \cdot 30$ & $2 \cdot 55$ & - \\
\hline Slavic (2002) & $35 \cdot 0$ & $1 \cdot 10$ & $1 \cdot 30$ & - \\
\hline
\end{tabular}

Table 3. Natural frequencies obtained by different authors in masonry towers
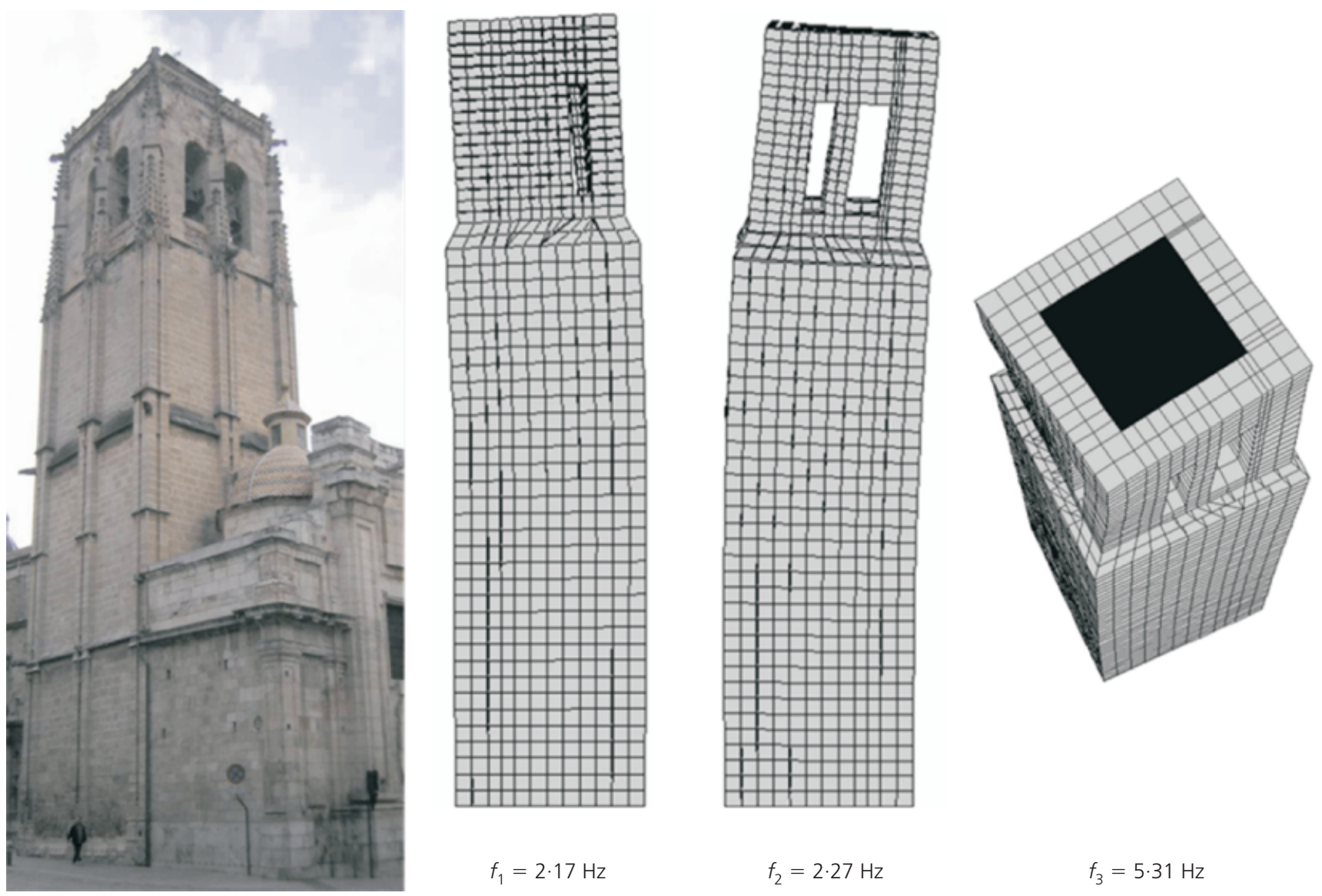

$f_{1}=2 \cdot 17 \mathrm{~Hz}$ $f_{2}=2 \cdot 27 \mathrm{~Hz}$

$f_{3}=5 \cdot 31 \mathrm{~Hz}$

Figure 4. Bell tower of St. Justa and Rufina (Orihuela, Spain). First, second and third vibration modes 


Ramping Observations
ratio: \%

\begin{tabular}{lll}
\hline Benedettini and Gentile (2007) & 1.43 & Teramo Cathedral \\
DIN 4178 (DIN, 2005) & 1.59 & Recommendation for masonry \\
Gentile and Saisi (2007) & 2.50 & Civic Tower in Pavia \\
Julio et al. (2008) & 0.61 & Coimbra University Tower \\
Schmidt (2007) & 2.11 & Dom Halberstadt Church \\
& 0.82 & St. Johannes Magdeburg \\
& 1.24 & Dom Magdeburg Church \\
& 1.07 & St Johannes Schobebecj \\
Wilson and Selby (1993) & 1.60 & Durham Cathedral
\end{tabular}

Table 4. Damping factor obtained experimentally by different authors

When the dynamic parameters of the tower are obtained, the dynamic amplification factor can be obtained from either very simple or advanced models, and thus the possible interaction between excitation and natural frequencies can be analysed.

\section{Forces generated by the ringing of the bells}

When bells are rung they generate a series of inertia forces on their supports that vary through time. The size of these forces depends on: the weight of the bell itself, the position of the centre of gravity in relation to the turning axis, bell inertia and turning speed. They can also be divided into vertical and horizontal components. The stiffness of masonry towers in the axial direction is considerable as compared with bending stiffness, so that the forces that comprise the horizontal component will be the major source of problems for this type of structure.

According to the bell-ringing system under consideration (English, Central European or Spanish), the values given for frequencies, type of turning/oscillation and position of the centre of gravity will vary, so that the forces transmitted to the tower will also vary. In order to underline this effect, Figures 5, 6 and 7 show the variation through time of the horizontal force that a bell weighing $90 \mathrm{kN}$ transmits to its supports when rung in each of the three systems. Each time graph is accompanied by a frequency analysis, which shows that in the Central European system the predominant harmonic is the second horizontal force: that is, the third of the total of the inertia forces transmitted to the supports, since the vertical component harmonic is not observed in this case. Likewise, it can be seen that the predominant harmonic in the English system is that corresponding to the third - that is, the fifth of the total excitation force and in the case of the Spanish system it is the first.

Since the harmonics corresponding to the excitation force are relatively low and close to the tower's natural frequencies, a dynamic interaction between the horizontal force and the tower's natural frequencies is quite likely. On occasions, the value of the

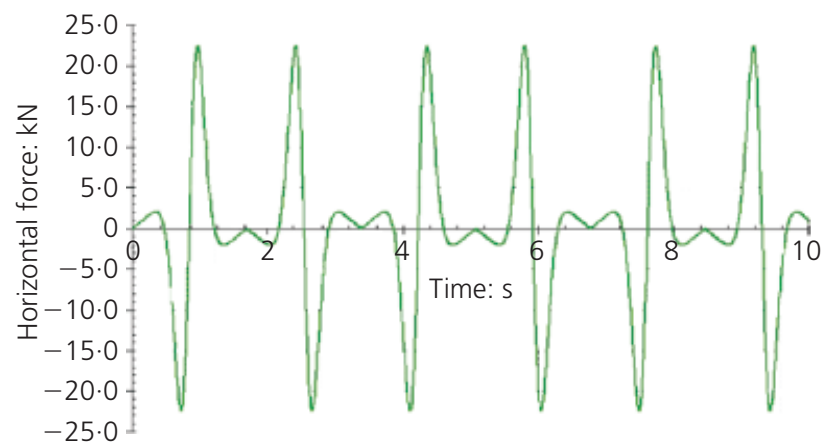

(a)

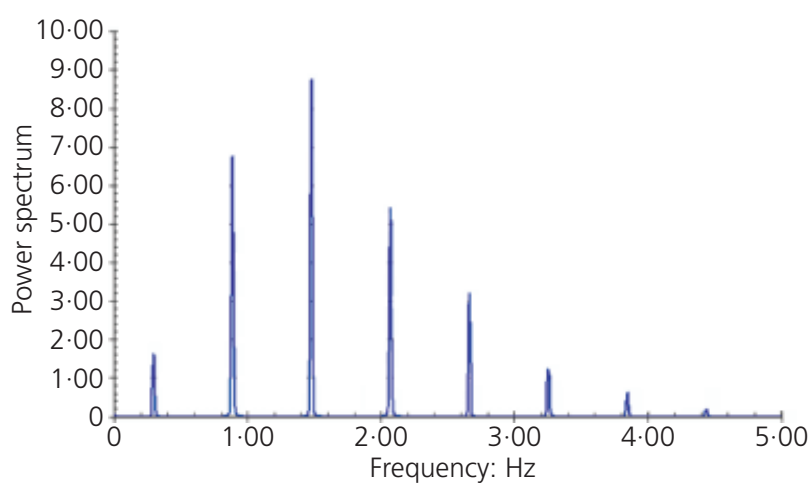

(b)

Figure 5. Horizontal forces and their harmonics (FFT analysis) generated by a bell turning in the English bell-ringing system

horizontal statically equivalent force introduced can be five times greater than the weight of the bell.

The total force transmitted to the supports in a given direction is the total of the horizontal forces of all the bells in the tower that turn in that direction at any given time. In order to reduce this force to the minimum, the arrangement of the bells within the belfry is usually carefully considered. Figure 8 shows the layout of a bellframe for a set of six bells arranged in pairs to achieve 
Masonry bell towers: dynamic

considerations

Ivorra, Pallarés and Adam

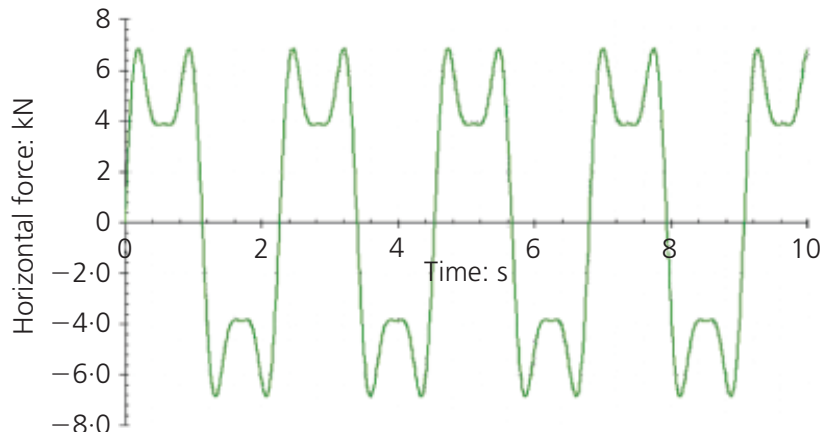

(a)

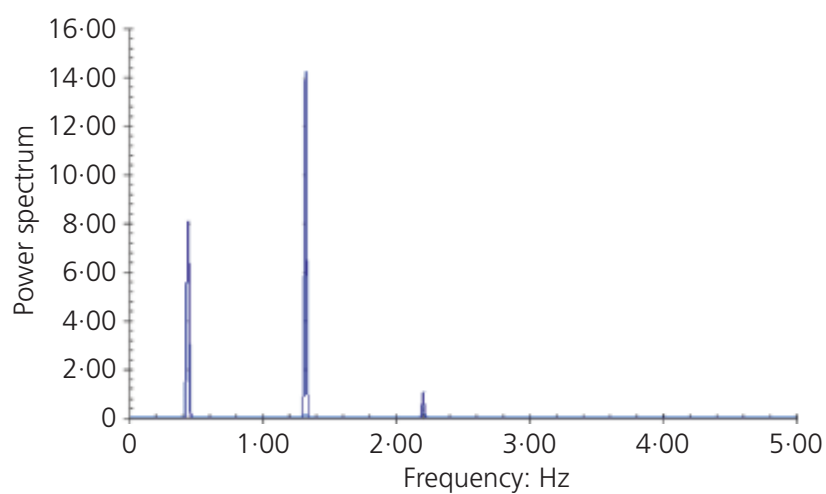

(b)

Figure 6. Horizontal forces and their harmonics (FFT analysis) generated by a bell turning in the Central European bell-ringing system

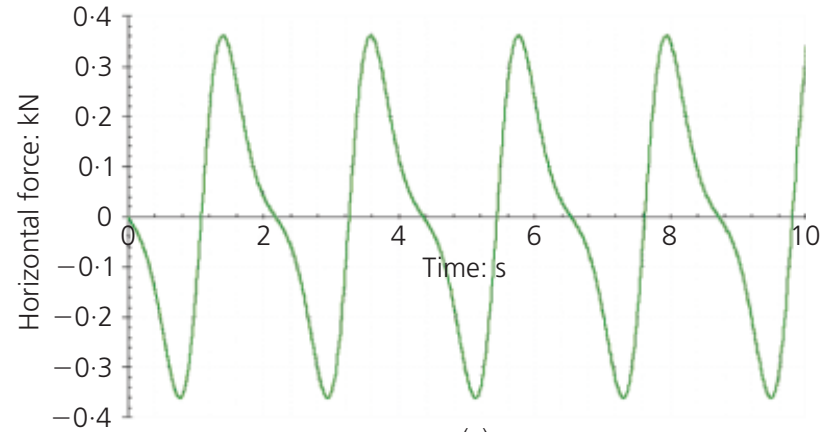

(a)

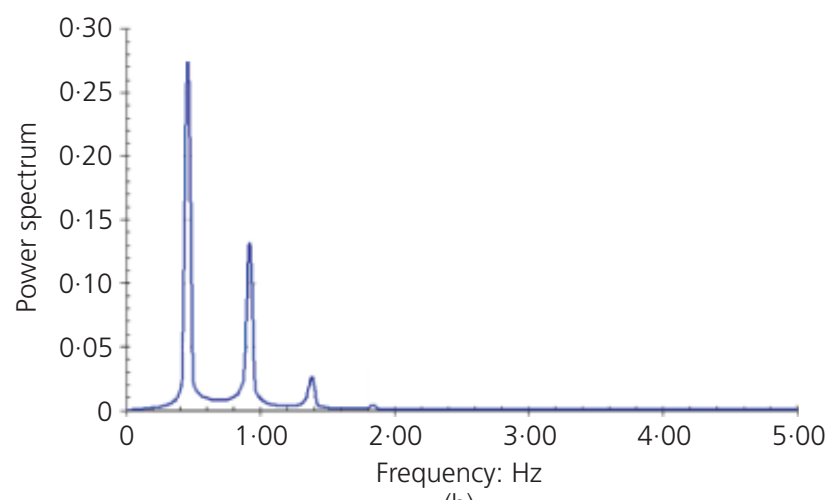

(b)

Figure 7. Horizontal forces and their harmonics (FFT analysis) generated by a bell turning in the Spanish bell-ringing system

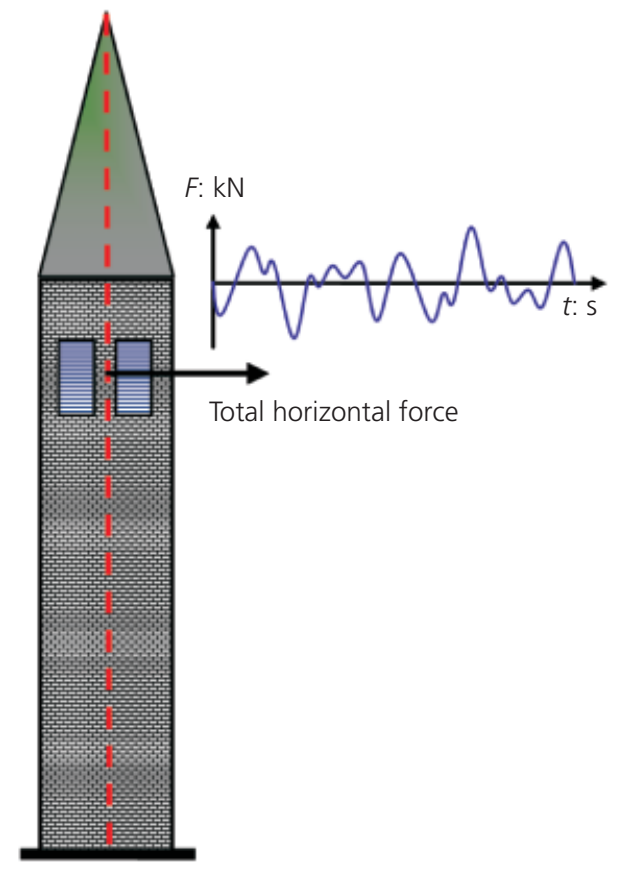

(b)

Figure 8. Arrangement of bells and their direction of turning in a belfry: (a) bellframe; (b) total horizontal forces exerted on the tower's central axis 
the minimum generated horizontal force when all the bells are rung at the same time. Since each bell has a different oscillation frequency, by means of a study of the characteristics of each one, a layout can be obtained in which the bells cancel out the effects of each other's horizontal forces. A detailed study of bell arrangements can be consulted in The Towers and Bells Handbook, published by The Central Council of Church Bell Ringers (1973).

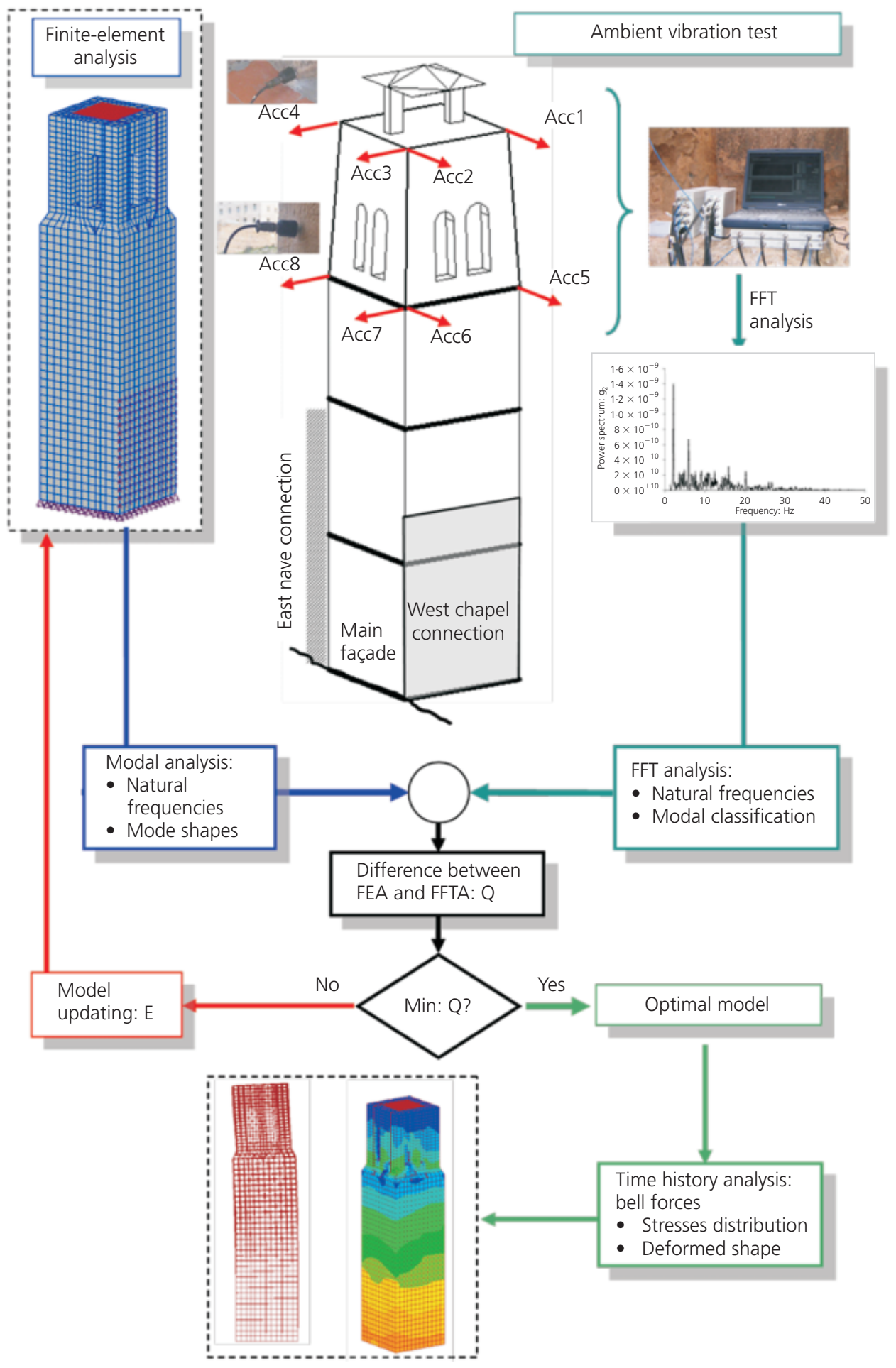

Figure 9. Dynamic-based assessment of a masonry belltower 


\section{Normal assessment procedures}

At the present time, the techniques for inspecting and assessing the dynamic behaviour of bell towers consists of measuring the structure's natural frequencies by means of accelerometers and comparing these with the bells' oscillation frequencies.

In certain cases, this work can be combined with three-dimensional numerical models to simulate interaction between the frequencies. Displacements and the forces exerted on the towers are evaluated to enable decisions to be taken regarding structural strengthening and/or changing the bells' mechanical operating system. Figure 9 shows a scheme of the procedure used to calibrate a numerical model with experimental data. This model can be used to carry out a more detailed study using a time history analysis of the horizontal forces exerted by the swinging movement of each bell.

\section{Summary and discussion}

From the preceding analysis the following conclusions can be made.

(a) Each bell tower is a unique element with its own geometric characteristics, placement and construction materials.

However, it can be stated that masonry towers have relatively low natural frequencies and a low damping coefficient.

(b) From the studies carried out to date on bell towers it can be said that the first two vibration modes are those of bending, are uncoupled, and correspond to orthogonal directions (e.g. $\mathrm{N}-\mathrm{S}, \mathrm{E}-\mathrm{W})$.

(c) According to DIN 4178 (which deals with the Central European bell-ringing system), there must be a difference of at least $20 \%$ between the value of the third bell harmonic and the first natural frequency of the tower in the turning direction of the bell. In the case of the English bell-ringing system, the interaction between the third and fifth harmonic of the forces generated by the bells must be evaluated. In the Spanish system, this difference must be considered with respect to the first harmonic of the forces generated by the turning of the bells.

(d) The appropriate arrangement of the bells in the bellframe can considerably reduce the dynamic interaction between bell and bell tower.

(e) It is much less expensive to modify the excitation frequency of the bells or to fit the bell yokes with counterweights than to modify the natural frequencies of the tower by structural strengthening.

\section{Conclusions}

Masonry bell towers have a unique dynamic behaviour owing to the structural characteristics of the tower itself and also due to the wide disparity that exists among masonry parameters. One of the strongest forces to which these structures are subjected is caused by the turning/oscillation action of the bells. This force varies according to the operating system used.

To characterise any possible interaction between the structure's natural frequencies and the horizontal forces generated by the turning/oscillation of the bells, analyses of the tower's dynamic characteristics, arrangement of the bells in the belfry and of their turning speeds must be carried out. The quasi-static value of this latter action can reach five times the weight of the bell itself, which means that this factor should be given special attention.

\section{REFERENCES}

Abruzzese D and Vari A (2004) Seismic resistance of masonry towers. Proceedings of the 4th International Seminar on Structural Analysis of Historical Constructions, Padova, $451-460$

Bennati S, Nardini L and Salvatore W (2005a) Dynamic behavior of a medieval masonry bell tower. Part I: Experimental measurements and modeling of bell's dynamic actions. Journal of Structural Engineering 131(11): 1647-1655.

Bennati S, Nardini L and Salvatore W (2005b) Dynamic behavior of a medieval masonry bell tower. Part II: Measurement and modelling of the tower motion. Journal of Structural Engineering 131(11): 1656-1664.

Benedettini F and Gentile G (2007) Ambient vibration testing and operational modal analysis of a masonry tower. Proceedings of the 2nd International Operational Modal Analysis Conference (IOMAC), Copenhagen, pp. 451-460.

Binda L, Corradi R, Falco M et al. (2000) Static and dynamic Studies on the Torrazzo in Cremona (Italy): the highest masonry bell tower in Europe. Proceedings of the IASS MSU International Symposium, Bridging Large Spans from Antiquity to the Present, Istanbul, pp. 100-110.

Carpinteri A, Invernizzi S and Lacidogna G (2005) In situ damage assessment and nonlinear modelling of a historical masonry tower. Engineering Structures 27(3): 387-395.

Clouston RWM (1970) Movements in church structures. Conference for architects Bedford College, London. In Central Council of Church Bell Ringers, unpublished document.

DIN (Deutsches Institut für Normung) (2005) DIN 4178 Glockentürme: Berechnung und Ausfhrung. DIN, Berlin, in German.

Niederwanger G (1985) Dynamische Messungen an Bauwerken underen Auswertung, Osterr. Ingenieur - und ArchitektenZeitschrift 2: 52-54, in German.

Gentile C and Saisi A (2007) Ambient vibration testing of historic masonry towers for structural identification and damage assessment. Construction and Building Materials 21(6): $1311-1321$.

Heywood AP (1914) Bell towers and bell hanging - an appeal to architects. In Central Council of Church Bell Ringers, unpublished paper. 
Ivorra S and Pallares FJ (2006) Dynamic investigations on a masonry bell tower. Engineering Structures 28(5): 660-667.

Ivorra S and Pallares FJ (2007) A masonry bell tower assessment by modal testing. Proceedings of the 2nd International Operational Modal Analysis Conference (IOMAC), Copenhagen, 269-284.

Ivorra S, Palomo MJ and Verdu G (2005) Dynamic behaviour of a belfry caused by the swinging bells. International Journal of Solids and Structures 42(5-6): 1669-1680.

Ivorra S, Palomo MJ, Verdu G and Zasso A (2006) Dynamic forces produced by swinging bells. Meccanica 41(1): 47-62.

Julio ENBS, Rebelo CAS and Dias-da-Costa DASG (2008) Structural assessment of the tower of the University of Coimbra by modal identification. Engineering Structures 30(12): $3468-3477$.

Lund JL, Selby AR and Wilson JM (1995) The dynamics of bell towers - a survey in northeast England. Proceedings of the 4th International Conference on Structural Studies of Historical Buildings, Crete, 45-52.

Modena C, Valluzzi MR, Tongini Folli R and Binda L (2002) Design choices and intervention techniques for repairing and strengthening of the Monza cathedral bell-tower. Construction and Building Materials 16(7): 385-395.

Müller F (1968) Dynamische und statische Gesichtspunkte beim Bau von Glockentürmen. Badenia Verlag GmbH, Karslsruhe, in German.
Niederwanger G (1985) Dynamische Messungen an Bauwerken underen Auswertung, Osterr. Ingenieur - u. ArchitektenZeitschrift 2: 52-54, in German.

Schmidt T (2007) Dynamic behaviour of twin bell towers. Proceedings of 2nd International Operational Modal Analysis Conference (IOMAC), Copenhagen, 261-268.

Selby A and Wilson JM (1997) The structural safety and acceptability of bell towers. Structural Studies, Repairs and Maintenance of Historical Buildings (Sanchez S (ed.)). Computational Mechanical Publications, Southampton.

Slavic M (2002) Assessment of bell towers in Saxony. In Structural Dynamics, EURODYN 2002, Swets \& Zeitlinger, Lisse.

Steiner J (1986) Neukonstruktion und Sanierung von Glockentürmen nach statischen und dynamischen Gesichtspunkten. Badenia Verlag GmbH, Karslsruhe, in German.

The Central Council of Church Bell Ringers (1973) The Towers and Bells Handbook. The Central Council of Church Bell Ringers, Northamptonshire.

Wilson JM and Selby AR (1993) Durham cathedral tower vibrations during bell-ringing. In Engineering a Cathedral (Jackson MJ (ed.)). Thomas Telford, London.

Wölfel HP and Schalk M (1996) Schwingungen von Glockentürmen. Bautechnik 73. Ernst \& Sohn, Berlin, in German.

\section{WHAT DO YOU THINK?}

To discuss this paper, please email up to 500 words to the editor at journals@ice.org.uk. Your contribution will be forwarded to the author(s) for a reply and, if considered appropriate by the editorial panel, will be published as a discussion in a future issue of the journal.

Proceedings journals rely entirely on contributions sent in by civil engineering professionals, academics and students. Papers should be $2000-5000$ words long (briefing papers should be 1000-2000 words long), with adequate illustrations and references. You can submit your paper online via www.icevirtuallibrary.com/content/journals, where you will also find detailed author guidelines. 